\title{
Imagine a cidade: práxis plurais e a produção de lugares compartilhados
}

\author{
Imagine the city: plural praxis and the production \\ of shared places
}

\section{Imagine la ciudad: praxis plurales y la producción de locales compartidos}

Wagner de Souza Rezende, Doutor em Arquitetura e Urbanismo, Professor Adjunto da Universidade Federal de Goiás, Goiânia, Brasil.

E-mail:wagnerrezende@ufg.br (DORCID: https://orcid.org/0000-0001-7054-3615

Para citar este artigo: REZENDE, W. S. Imagine a cidade: práxis plurais e a produção de lugares compartilhados. Cadernos de Pós-Graduação em Arquitetura e Urbanismo, São Paulo, v. 22, n.1, p. 32-49, 2022. DOI 10.5935/ cadernospos.v22n1p32-49

Submissão: 2021-04-11

Aceite: 2021-09-21

\section{Resumo}

Este artigo trata dos processos de ação coletiva e colaboração técnica, partindo da premissa de que o projeto é um instrumento de transformação do território para a inovação social. Nesse sentido, "imagine paraisópolis" foi uma experiência colaborativa de projeto urbano em assentamentos precários, cujo principal objetivo foi a troca de saberes, práticas e experiências entre profissionais e estudantes de arquitetura e urbanismo e adolescentes, moradores de Paraisópolis, uma favela na cidade de São Paulo, para a produção colaborativa de lugares compartilhados. Organizado em torno de cinco práxis plurais - estratégia, colaboração, experimentação, reflexão e expressão -, esta pesquisa faz uma crítica ao projeto participativo na microescala. Desse modo, são apresentados conceitos que se inserem no debate urbano atual: "cidadania insurgente" como a resistência ao planejamento 
hegemônico; "práxis plurais" como processos colaborativos de projeto; "comuns urbanos", compreendidos como campos de ação nos espaços públicos; e, "lugares compartilhados", territorialidades favoráveis à presença e à diferença no espaço público. Com este estudo, buscar meios de melhoria da vida cotidiana na cidade, privilegiando o ser humano e as relações sociais como essenciais à cidade, mostrou-se como uma oportunidade para reflexão sobre o papel das práxis plurais na produção de lugares compartilhados.

Palavras-chave: Práxis plurais; Paraisópolis; Comuns urbanos; Lugares compartilhados; Cidadania insurgente.

\begin{abstract}
This article approaches the processes of collective action and technical collaboration, starting from the premise that the project is an instrument of transformation of the territory toward social innovation. In this sense, "imagine paraisópolis" was a collaborative experience of urban design in informal settlements, whose main objective was the exchange of knowledge, practices and experiences, between professionals and students of architecture and urbanism and adolescents, residents of Paraisópolis, a slum in the city of São Paulo, for the collaborative production of shared places. Organized around five plural praxis - strategy, collaboration, experimentation, reflection and expression - this article criticizes the participatory project in the microscale. Thus, concepts that are part of the current urban debate - "insurgent citizenship" as resistance to hegemonic planning are presented; "plural praxis" as collaborative project processes; "urban commons", fields of action in public spaces; and, finally, "shared places", territorialities favorable to the embodied presence and difference in public space. Thinking about ways to improve everyday life in the city, favoring the human being and social relations as essential to the city, proved to be an opportunity for reflection on the role of plural praxis in the production of shared places.
\end{abstract}

Keywords: Plural praxis; Paraisópolis; Urban Commons; Shared places; Insurgent citizenship.

\title{
Resumen
}

Este artículo trata de procesos de acción colectiva y colaboración técnica, desde de la premisa de que el proyecto es un instrumento de transformación del territorio hacia la innovación social. En este sentido, "imagine paraisópolis" fue una experiencia colaborativa de diseño urbano en asentamientos informales, cuyo objetivo principal fue el intercambio de conocimientos, prácticas y experiencias, entre profesionales y estudiantes de arquitectura y urbanismo y adolescentes, residentes de Paraisópolis, un barrio popular en la ciudad de San Pablo, para la producción colaborativa de lugares compartidos. Organizado en torno a cinco praxis plurales - estrategia, colaboración, experimentación, reflexión y expresión - este artículo critica el proyecto participativo en la microescala. Así, se presentan conceptos que forman parte del debate urbano actual - "ciudadanía insurgente" como resistencia a la planificación hegemónica; "praxis plural" como procesos de proyectos colaborativos; "comunes urbanos", campos de acción en espacios públicos; y, por último, "lugares compartidos", territorialidades favorables a la diferencia en el espacio público. Pensar el mejoramiento de la vida cotidiana en la ciudad, favoreciendo al ser humano y las relaciones sociales como esenciales para la ciudad, resultó ser una oportunidad para reflexionar sobre el papel de la praxis plural en la producción de lugares compartidos.

Palabras clave: Praxis plural; Paraisópolis; Comunes urbanos; Lugares compartidos; Ciudadanía insurgente. 


\section{INTRODUÇÃO}

\section{Alternativas para Imaginar a Cidade}

Q uando, em 2016, o arquiteto chileno Alejandro Aravena foi agraciado com o Pritzker por seu engajamento na prática do urbanismo social - especialmente nos projetos de habitação de interesse social, utilizando ferramentas participativas de gestão do habitar -, reafirmou-se a importância do urbanismo tático e reestabeleceu-se o papel dos arquitetos e arquitetas como catalizadores, ativistas, críticos, produtores ou mediadores, diante das demandas por espaços públicos nas áreas de vulnerabilidade social.

Em um estudo sobre ações colaborativas, Manzini (2015) discute os desafios performáticos, substantivos e contextuais associados aos projetos orientados para a inovação social. O estudioso define a inovação social como uma abordagem que propõe alternativas de mundo que valorizam, simultaneamente, a mudança societária por meio de novos projetos e a formação de redes sociotécnicas de cooperação que fomentem o protagonismo das comunidades locais nas políticas públicas urbanas.

Posto isso, esta pesquisa pretende explorar o alcance e os limites dessas redes colaborativas, a partir do registro de uma experiência de extensão universitária que ocorreu na favela de Paraisópolis, um assentamento precário, localizado em uma área de concentração de alta renda de São Paulo.

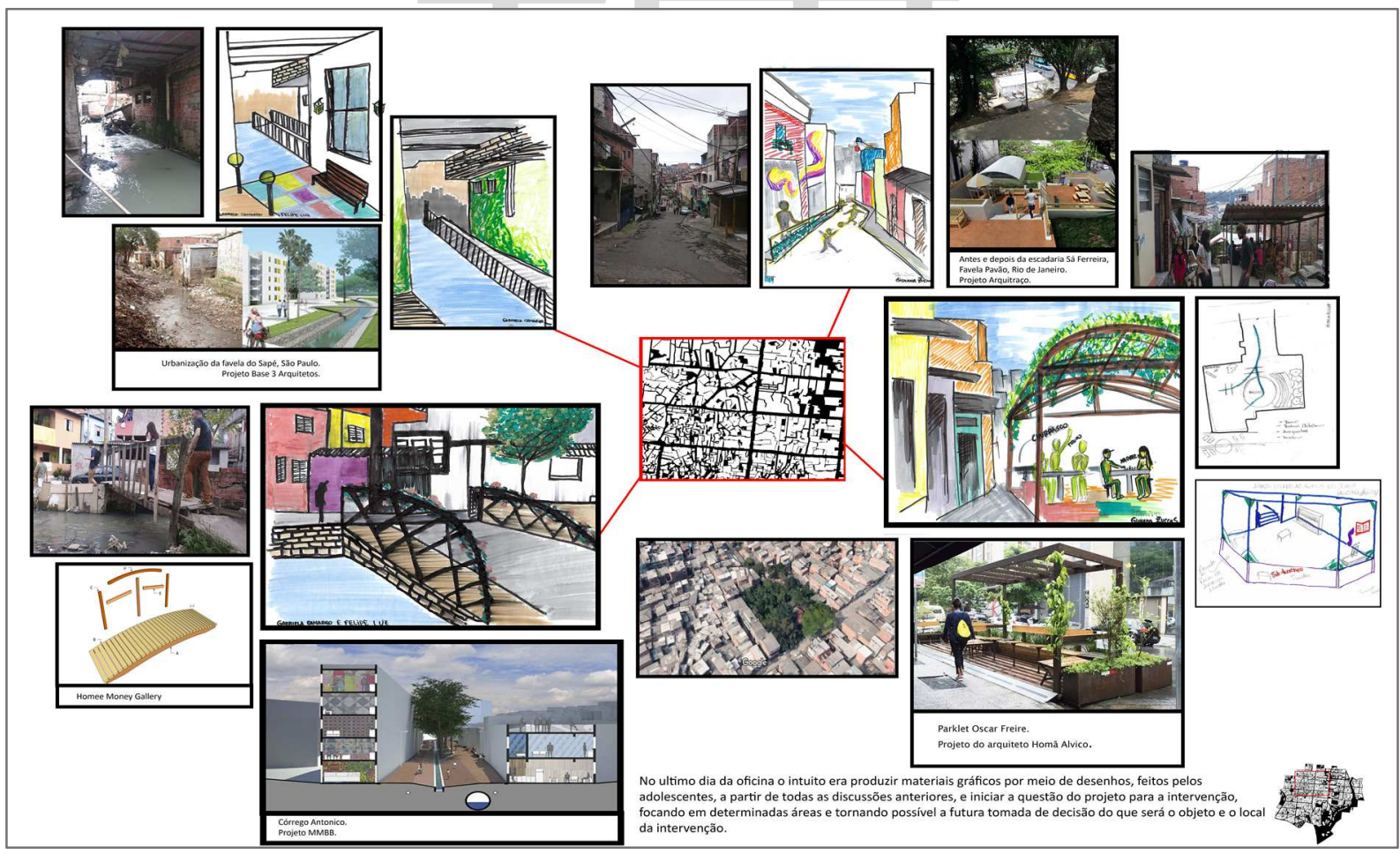

Figura 1: Pôster para divulgação das Práxis Plurais em exposição realizada no CEU Paraisópolis. Fonte: acervo do autor, 2017. 
Se, de um lado, diversos estudiosos defendem a importância dos governos locais como agentes articuladores das políticas públicas redistributivas de renda, de outro, o protagonismo dos movimentos sociais torna-se evidente em várias partes do mundo, especialmente no Brasil, onde a abordagem participativa em projetos urbanos é relativamente recente (HARVEY, 1997). Atualmente, as pesquisas interdisciplinares dedicadas à observação de práticas participativas na produção dos comuns urbanos têm se expandido para além dos movimentos sociais institucionalizados. ${ }^{1}$

No horizonte da crise da urbanização vivenciada em nível global, nos apoiamos na teoria urbana crítica, tal como exposta por Brenner (2018), para indicar algumas abordagens, convergentes e concorrentes entre si, a saber: urbanismo participativo, um modelo de urbanização institucionalizado pelas formas neoliberais de governança urbana; urbanismo insurgente, uma forma de pensar a cidade que se apoia nas práticas de experimentação radical, mais impulsivas e espontâneas; e urbanismo tático, um conjunto complexo de ações fundamentadas na geração estruturada de alternativas ao paradigma neoliberal de intervenção urbana, objetivando a apropriação equitativa do espaço urbano e a justiça socioespacial redistributiva. ${ }^{2}$

O engajamento da sociedade civil nos processos de decisão das políticas públicas poderia conter três instâncias de envolvimento popular em processos urbanos: uma informativa, incluía qual compreende as práticas de manipulação, a terapia e a informação; uma consultiva, que inclui o uso de estratégias consultivas e de coalizão entre grupos que detêm poder de decisão; e uma deliberativa, referente à parceria, à delegação e a gestão, modalidades que definem o gerenciamento compartilhado das ações para o desenvolvimento local (ARNSTEIN, 1969).

Os processos urbanos são conjuntos de ações assimétricas que moldam a paisagem urbana continuamente, como mediadores das relações de ativação do desenvolvimento socioespacial ou como instrumentos de apropriação dos comuns urbanos a serviço do capital.

Com uma ecologia de saberes que supere as distinções entre conhecimentos científicos e não-científicos, objetiva-se práxis plurais na (re)configuração das epistemologias do sul, contra o colonialismo e as práticas capitalistas heterônomas que se vinculam ao pensamento abissal; entendido no sistema de distinções culturais e regulações, visíveis e invisíveis, que impossibilitam a copresença de formas científicas e não-científicas, tais como conhecimentos populares, leigos, camponeses ou indígenas.

Assim, esse artigo propõe o pensamento pós-abissal como ponto de partida para se pensar as práxis plurais, uma perspectiva de resistência política cuja condição essencial seria a "copresença radical" na articulação dos comuns urbanos, especialmente associada aos conceitos de lugar e cotidiano, por meio de práticas espaciais orientadas para o desenvolvimento socioespacial.

1 Podemos nos deter nos exemplos de Suri (2003), Ehn (2008), Cámara (2012), Del Gaudio (2016), Montaner (2017) e Huybrechts (2016).

2 A discussão sobre os modelos de urbanização neoliberal ultrapassa o escopo deste artigo, mas sugerimos a leitura dos textos de Harvey (1989) e Brenner (2018) 


\section{Comuns Urbanos}

Nossa abordagem à noção de comuns urbanos segue o debate atual sobre o tema e distingue três raízes conceituais: comum, comuns e comunalidade (HESS, 2008; BORCH; KORNBERGER, 2015; FOSTER; LAIONE 2016; PARKER; SCHMIDT, 2017; CRUZ; PAULINO, 2020; FEINBERG et al., 2021). O termo "comum" descreve a fundação de recursos materiais e simbólicos compartilhados, com os quais a humanidade pode viver em conjunto, abrangendo desde recursos naturais até riqueza digital (HARDT; NEGRI, 2009). Os "comuns" representam bens mútuos resultantes da dinâmica institucional e dos arranjos construídos sobre a base do comum (TELI et al., 2015). O processo de produção dos comuns se reflete na "comunalidade", prática socioespacial que liga um recurso à sua coletividade próxima (FOSTER; LAIONE, 2019).

Como desdobramento de um debate mais amplo sobre os "comuns", os fundamentos teóricos e conceituais sobre os comuns urbanos têm sido construídos ao longo das últimas décadas. Enquanto Hardin (1968) elaborou sua crítica aos comuns, defendendo a privatização das estruturas econômicas, Ostrom (1990) demonstrou que as lógicas que regem os mecanismos coletivos de criação e gestão dos bens comuns podem viabilizar o desenvolvimento social sustentável.

Em um contexto neoliberal de urbanização que tende a construir e destruir continuamente os comuns urbanos, destituindo de sentido a ideia do direito à cidade, pode-se dizer, então, que os bens comuns urbanos são continuamente produzidos pelo trabalho coletivo, para serem, após sua valorização imobiliária, apropriados pelo capital em sua forma mercantilizada e monetizada, como pela expansão da gentrificação nas áreas requalificadas pelo poder público. Assim, a política dos bens comuns urbanos deve ser insituída para a sua produção, sua proteção e seu uso pela sociedade, em um contexto de enfrentamento à degradação do trabalho e dos recursos naturais (HARVEY, 2014).

Contrapondo as opiniões de Hardin (1968) e Ostrom (1990) sobre a noção de comuns, duas abordagens-chave emergem a partir de narrativas semelhantes com as quais os críticos trazem novas teorias para as economias anticapitalistas ao debate. Nessas novas teorias, o significado dos comuns é construído a partir da noção de comunidade e evolui de um pensamento neomarxista (HESS, 2008; HARDT; NEGRI, 2009; DARDOT; LAVAL, 2016).

A primeira abordagem advém da teoria dos comuns urbanos, que pode ajudar a elucidar os conflitos sociais, políticos e econômicos que emergem no processo de comoditização dos espaços urbanos nas cidades em todo o mundo (HARVEY, 2014; STAVRIDES, 2016); uma vez que propõe revestir as discussões sobre os comuns aplicadas ao contexto urbano, a fim de refletir simultaneamente sobre cidades e comuns (BORCH; KORNBERGER, 2015). Como um comum urbano representa bens materiais, imateriais ou digitais, compartilhados em um ambiente urbano, destina-se a ser um ativo para o bem-estar coletivo, e a sua degradação (dos comuns) é percebida como uma perda, visto que ela é construída em torno das questões sociais de participação e auto-organização que se refletem através do termo comum: criar coletivamente, usar e gerenciar os comuns (LINEBAUGH, 2008). 


\section{Lugares Compartilhados}

O conceito de "lugar compartilhado" apresentado aqui é fundamentado por Agnew (1987; 1993), Moore (2013) e Souza (2013), bem como da interpretação dos comuns urbanos apresentada no tópico acima. Nesse contexto, os moradores das periferias tornam-se os construtores das novas áreas de uso comum, atuando, através das práticas cotidianas, sobre os tecidos urbanos fragmentados.

Consequentemente, as ruas são muito mais usadas como espaço de convivência cotidiana, expressão popular e manifestações democráticas. Lugares compartilhados podem emergir de festas religiosas, festivais culturais, performances artísticas e atividades esportivas, e por movimentos sociais com foco no desenvolvimento socioespacial em resposta a demandas relacionadas a infraestrutura, mobilidade urbana ou requalificação de espaços públicos (ROSA, 2011).

\section{Cidadania Insurgente}

A partir dos anos 1960, contrariando o planejamento urbano hegemônico, diversos autores reafirmaram a importância do uso de métodos participativos de decisão na melhoria da qualidade de projetos de espaços públicos. ${ }^{3}$ Nesse sentido, processos participativos para o desenvolvimento local orientados por diálogos democráticos se destacam, especialmente no contexto europeu (HUYBRECHTS et al., 2016).

Trata-se, assim, de um quadro conceitual que reafirma o engajamento político nos processos de projeto e enfatiza os agenciamentos dos recursos locais, que alguns autores denominam "infraestruturação" (DEL GAUDIO, 2017). A chave para o entendimento dessas práticas está na adoção de uma política de conflitos, descrita por Mouffe (2015), como democracia agonística.

Em oposição às políticas de governança, a cidadania insurgente incide sobre as sociabilidades, produzidas na e pela cidade, que remetem às "práticas espaciais insurgentes" sugeridas por Souza (2013). No entanto, na outra ponta dos movimentos sociais em prol dos espaços públicos, o que muitos desses grupos ativistas parecem querer promover é o acesso público e democrático a espaços urbanos mais qualificados e a serviços básicos de infraestrutura, habitação e mobilidade urbana (WISNIK, 2016).

Como resultado do desenvolvimento das periferias urbanas autoconstruídas, responsáveis pelas modalidades de participação democrática que vêm transformando profundamente a sociedade brasileira, a cidadania insurgente pode ser entendida como uma alternativa ao regime de cidadania formal, institucionalizada pelo Estado (HOLSTON, 2013). Dessa forma, o papel dos profissionais dedicados à transformação social da cidade, idealmente, é o de representar e defender o que há de melhor para as pessoas que, mesmo sendo afetadas pelos projetos, normalmente não tomam parte no processo decisório.

3 Dentre esses autores, detaca-se Lacaze (1993), Jacobs (2000), Rosa (2011), Alexander (2013), Gehl (2013) e Fontes (2013). 


\section{Práxis Plurais}

Práxis plurais são práticas espaciais orientadas para o desenvolvimento socioespacial, que pretendem articular a episteme, a doxa, os saberes tradicionais e o conhecimento científico, associando as questões urbanas mais complexas habitação, saúde, educação, mobilidade, trabalho, economia - às barreiras da vida cotidiana (CARLOS, 2018).

Pensando a cidade como processo e articulando ações de inovação social, as práxis plurais potencializam as diversas fases do projeto urbano. O Quadro 1 demonstra como essas práxis foram exploradas em uma pesquisa-ação desenvolvida na favela Paraisópolis, localizada em São Paulo, cuja abordagem consistiu em cinco perspectivas - estratégica, experimental, insurgente, reflexiva e, expressiva - associadas, respectivamente, às cinco etapas da oficina de projeto "Imagine Paraisópolis".

A práxis estratégica é associada às articulações políticas das questões que, diante de contextos complexos, promovam alternativas viáveis de melhoria das condições ambientais dos agentes envolvidos. No momento da práxis experimental, os participantes produzem cartografias (afetivas) que desvelam espaços, sentidos, emoções, imaginários, paisagens e linguagens "invisíveis". São nessas ações (etnografias urbanas) que se envolvem os diversos agentes, que dialogam entre si sobre as possíveis ações de desenvolvimento socioespacial - são eles: lideranças locais, patrocinadores e instituições públicas vinculadas a setores de planejamento urbano e governança.

Já a práxis insurgente permite pensar e agir coletivamente, considerando o momento presente e a perspectiva do espaço relacional, o que contrasta com abordagens mais tradicionais do ativismo de design. Aqui, o arquiteto ou arquiteta que assume o papel de ativista se engaja em iniciar mudanças para imaginar e criar "futuros melhores" em contextos vulneráveis por meio de redes relacionais (HALL, 2013). O ativismo urbano é caracterizado por ações insurgentes no espaço público e pode ser considerado como uma estratégia disruptiva, criando controvérsias que desequilibram o status quo do pensamento urbano hegemônico (CARLOS, 2015).

A práxis reflexiva, por sua vez, organiza os processos de tomada de decisão, tornando explícitas vozes alternativas, agendas contraditórias e agências concorrentes dos atores envolvidos, agenciando, assim, o pluralismo agonístico das disputas políticas entre públicos heterogêneos (MOUFFE, 2015). Assim, tanto urbanistas, como a população em geral atuam na produção de cartografias (afetivas) que promovem a visibilidade de espaços, sentidos, emoções, imaginários, paisagens e linguagens "invisíveis".

Por fim, a práxis expressiva refere-se, principalmente, às redes sociotécnicas que estruturam e apoiam ações estratégicas advindas do engajamento dos diversos públicos envolvidos no processo de projeto. Desse modo, os especialistas atuam na formação de públicos por meio de projetos, podendo divulgar e sustentar propostas existentes, bem como gerar novas ações locais coordenadas entre si. O que essa divulgação e criação de compromissos (engajamentos) compartilha com a práxis estratégica é o interesse na constante articulação das relações que existem e se desenvolvem dentro de processos complexos dos projetos urbanos. 


\begin{tabular}{|c|c|c|}
\hline $\begin{array}{l}\text { Práxis Plurais } \\
\text { (Especialistas) }\end{array}$ & Atividades & $\begin{array}{l}\text { Ferramentas } \\
\text { (Produtos) }\end{array}$ \\
\hline $\begin{array}{c}\text { Estratégica } \\
\text { (especialistas atuam } \\
\text { como estrategistas) }\end{array}$ & $\begin{array}{l}\text { Encontros com lideranças locais } \\
\text { para alinhar os temas e } \\
\text { discussões das ações necessárias } \\
\text { para a realização do projeto da } \\
\text { praça. }\end{array}$ & $\begin{array}{l}\text { Entrevistas; questionários; } \\
\text { ideação; encontros (filmes, } \\
\text { fotografias; atlas da vida } \\
\text { cotidiana). }\end{array}$ \\
\hline $\begin{array}{l}\text { Experimental } \\
\text { (especialistas atuam } \\
\text { como produtores) }\end{array}$ & $\begin{array}{l}\text { Debater com os públicos locais } \\
\text { ideias e pensamentos que } \\
\text { ensejem na resolução de } \\
\text { conflitos relacionados ao tema } \\
\text { em discussão. Desenvolver um } \\
\text { modelo de processo interativo } \\
\text { que favoreça a evolução da } \\
\text { percepção da paisagem local por } \\
\text { parte dos moradores. }\end{array}$ & $\begin{array}{l}\text { Oficinas criativas colaborativas; } \\
\text { reuniões realizadas aos fins de } \\
\text { semana com o objetivo de } \\
\text { produzir ideias para espaços } \\
\text { públicos locais } \\
\text { (ideias de praças, espaços } \\
\text { públicos, áreas de lazer. desenhos } \\
\text { diversos realizados pelos } \\
\text { moradores locais). }\end{array}$ \\
\hline $\begin{array}{c}\text { insurgente } \\
\text { (especialistas atuam } \\
\text { como ativistas) }\end{array}$ & $\begin{array}{l}\text { Interação social por meio da } \\
\text { apropriação dos espaços públicos } \\
\text { e culturais, de modo } \\
\text { experimental, com o uso de } \\
\text { protótipos (ideias, experiências e } \\
\text { objetos). Incentivar os públicos } \\
\text { interessados em } \\
\text { microintervenções urbanas a } \\
\text { conhecer o lugar da praça, } \\
\text { incentivando a renegociação das } \\
\text { sociabilidades. }\end{array}$ & $\begin{array}{l}\text { Prototipagem; urbanismo tático; } \\
\text { microintervenções urbanas; } \\
\text { grafite; arte urbana } \\
\text { (festa na rua. feira cultural. } \\
\text { Protótipos, ideias, experiências e } \\
\text { objetos). }\end{array}$ \\
\hline $\begin{array}{c}\text { Reflexiva } \\
\text { (especialistas atuam } \\
\text { como críticos) }\end{array}$ & $\begin{array}{l}\text { Documentar o processo do } \\
\text { projeto colaborativo para que } \\
\text { seja possível traçar os caminhos } \\
\text { percorridos desde o início dos } \\
\text { trabalhos, de modo a permitir o } \\
\text { questionamento e a autocrítica. }\end{array}$ & $\begin{array}{l}\text { Análise crítica; fórum de } \\
\text { discussão entre especialistas; } \\
\text { questionário } \\
\text { (publicações em revistas } \\
\text { especializadas. enquetes nas } \\
\text { redes sociais. relatório final). }\end{array}$ \\
\hline $\begin{array}{l}\text { Expressiva } \\
\text { (especialistas atuam } \\
\text { como mediadores) }\end{array}$ & $\begin{array}{l}\text { Divulgar o projeto em outras } \\
\text { instâncias, objetivando conectar } \\
\text { com outros públicos em uma } \\
\text { escala regional e global, } \\
\text { objetivando apoio político e } \\
\text { financeiro para concretização da } \\
\text { proposta em um processo } \\
\text { sustentável. }\end{array}$ & $\begin{array}{l}\text { Redes sociais; blog; divulgação } \\
\text { em sites de arquitetura e } \\
\text { urbanismo. }\end{array}$ \\
\hline
\end{tabular}

Quadro 1: Metodologia das Práxis Plurais. Fonte: Elaborado pelo ator, 2021. 


\section{Imagine Paraisópolis}

A proposta que fundamentou o projeto de extensão priorizou o intercâmbio de conhecimento, práticas espaciais e experiências entre especialistas, estudantes de arquitetura e urbanismo, adolescentes moradores de Paraisópolis, entre outros agentes, para a produção participativa de lugares públicos por meio de táticas urbanas.

O grande desafio dessa abordagem teórica e prática foi e é melhorar a vida cotidiana, na medida em que a vida humana se torna a principal referência na apropriação do ambiente construído. Entre os objetivos específicos podemos citar: mobilizar a comunidade local sobre a questão do espaço público; promover o intercâmbio de conhecimento entre moradores, estudantes de arquitetura e profissionais; produzir performances urbanas nos microterritórios escolhidos; documentar as oficinas em vídeo e fotografia; montar uma exposição com as pranchas resultantes; organizar um seminário com a participação de representantes dos diversos setores da sociedade civil, intitulado "Lugar Público na Periferia"; e bproduzir livro ou catálogo com material gráfico das oficinas, das exposições e do seminário.

\section{Metodologia}

Com respeito aos métodos empregados, é importante enfatizar a pesquisa-ação que permitiu orientar as atividades e organizar o processo colaborativo de projeto, especialmente no uso de diagramas como forma de aprendizado.

Thiollent (2011), explora a pesquisa-ação como um método ou conjunto de ferramentas para tentar entender, entre outras questões, o comportamento de grupos nos processos democráticos de produção de ideias. A pesquisa-ação consiste em uma ferramenta de avaliação de práticas de projeto que contribui na elucidação de questões sociais por intermédio do agenciamento sociotécnico de grupos heterogêneos diante de dilemas da realidade concreta. Nesse processo estão entrelaçados os efeitos da transformação social, experienciados durante a intervenção urbana, e os quadros conceituais, mobilizados durante a interpretação dos dados.

Como se trata de uma proposta de produção participativa de lugar que tem como premissa a apropriação de espaços públicos pelos moradores locais, o engajamento dos moradores com a proposta foi decisivo, pois eles representaram, em grande medida, as demandas e o capital social de toda a comunidade.

O número de participantes das oficinas - organizadas em cinco etapas, conforme apresentado acima no Quadro 1 -, sendo estudantes dos cursos de Arquitetura e Urbanismo e Design da FAU-Mackenzie, foi de 16 no total, sendo quatro integrantes por oficina. Entre os moradores locais, foram cerca de 60 participantes, indicados pelas assistentes sociais que trabalhavam no Projeto Einstein Paraisópolis. Ressalta-se também que a Fundação Alphaville participou do projeto como observadora e patrocinadora de algumas atividades. 


\section{Um sábado (in)comum no Antonico}

O grande desafio da oficina foi pensar, de forma conjunta, meios para melhorar a vida cotidiana dos habitantes de Paraisópolis, privilegiando o ser humano e as relações sociais como parte do fenômeno urbano. Dessa forma, "Imagine Paraisópolis" atuou como uma oportunidade para refletir, dialogar, projetar e agir sobre o espaço público. O interesse, o comprometimento e a atuação dos participantes foram muito importantes para a realização da exposição e da intervenção na comunidade.

A seguir, apresenta-se um relato resumido dos eventos que ocorreram entre 22 de fevereiro e 24 de junho de 2017, quando foi organizada a única intervenção, na região conhecida como Antonico, uma área ambientalmente vulnerável de Paraisópolis.

O principal produto da práxis estratégica foi o minicurso, que ocorreu nos dias 22 e 23 de fevereiro de 2017, no Núcleo de Arquitetura e Urbanismo da Mackenzie (NAU). O objetivo principal do curso foi apresentar, aos alunos e alunas, informações fundamentais sobre a proposta, dividida em dois pontos principais: a) informar sobre o contexto socioespacial de Paraisópolis, compreendendo evolução urbana, territorialidade, projetos urbanos, desenvolvimento local e apropriação de espaços públicos; e b) informar sobre urbanismo tático, pensamento diagramático, mapeamento colaborativo e táticas urbanas, além de discutir os papéis do especialista e do morador nesse método de projeto.

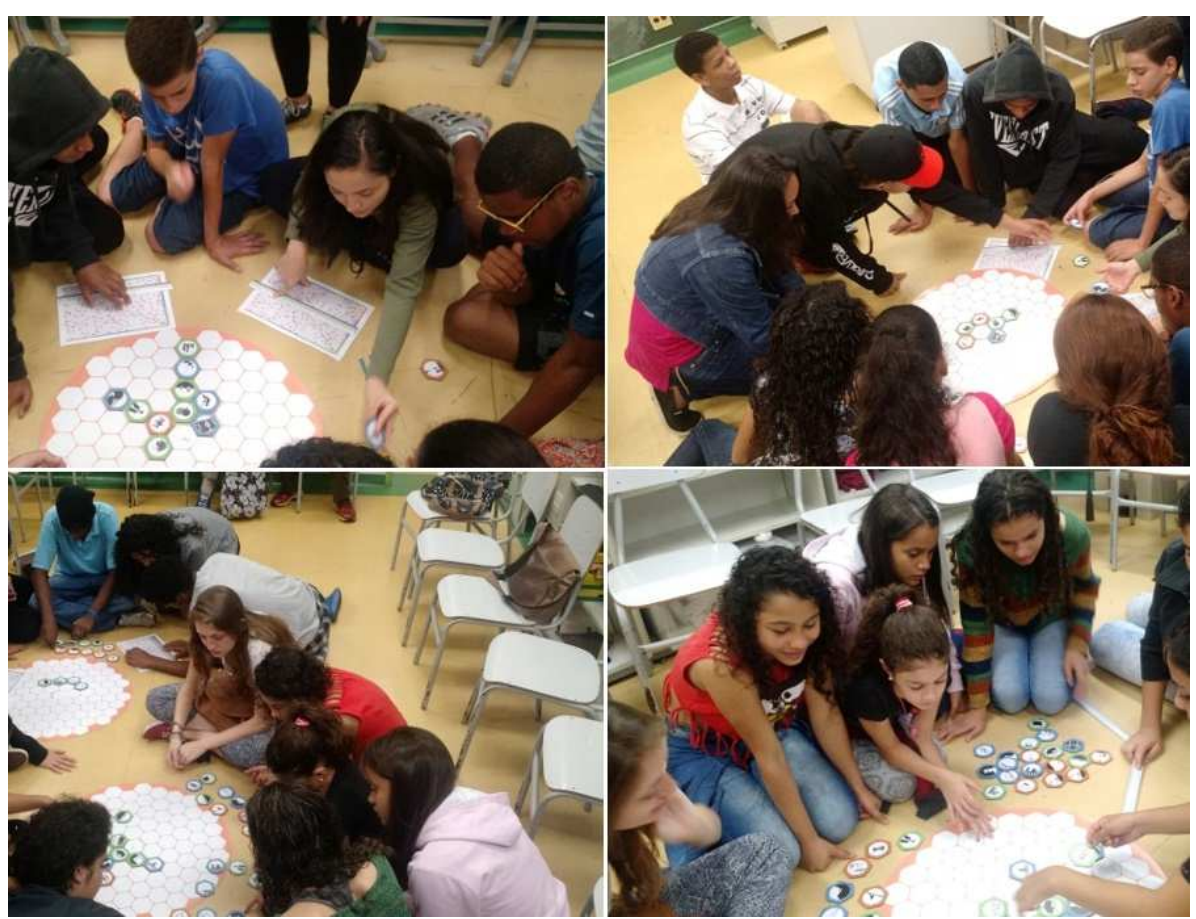

Figura 2: Práxis experimental: moradores de Paraisópolis participando de uma atividade de projeto urbano. Fonte: acervo do autor, 2017. 
A práxis experimental se constituiu na etapa do projeto colaborativo, organizada em quatro encontros consecutivos, aos sábados, no Projeto Einstein na Comunidade Paraisópolis. As atividades foram apresentadas na forma de jogos interativos que exploraram a capacidade de lidar com problemas complexos, como a identificação de potencialidades locais para a melhoria da qualidade ambiental.

As equipes foram agrupadas de acordo com as localidades: Antonico, Brejo, Centro e Grotinho.

No primeiro encontro, foram discutidas vivências concretas, que possibilitaram sensibilizar o olhar crítico sobre as relações na vizinhança e refletir sobre as necessidades e recursos disponíveis localmente, a fim de instrumentalizar os moradores para diagnósticos urbanos em microescala.

No segundo encontro, realizaram-se interpretações subjetivas, estimulando a reflexão sobre as alternativas futuras para a comunidade local, com o objetivo de promover e incentivar a participação dos moradores na melhoria das condições ambientais locais.

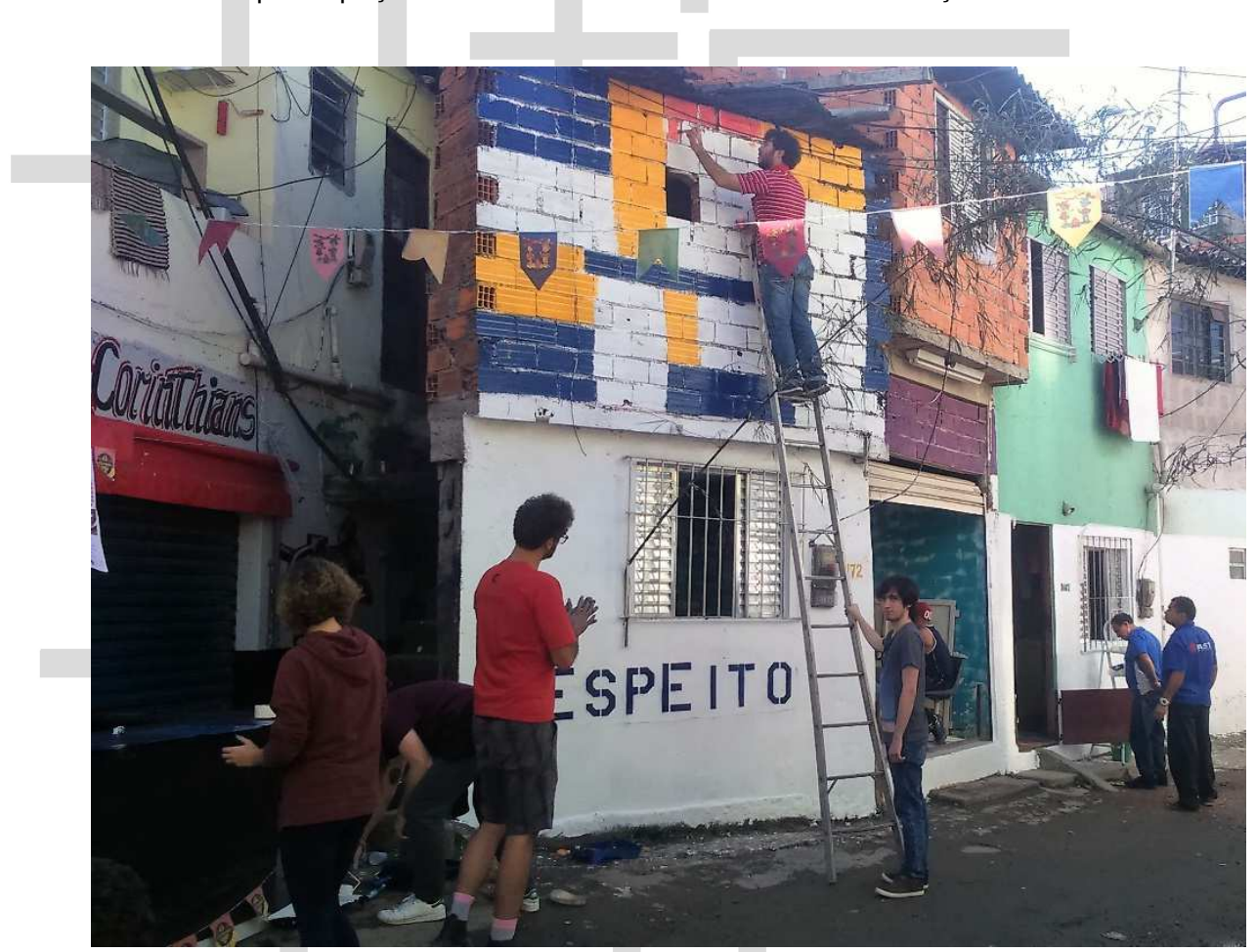

Figura 3: Práxis insurgente: pintura nas fachadas das casas localizadas no Antonico, área da favela de Paraisópolis. Fonte: acervo do autor, 2017.

O terceiro encontro teve como objetivo, bem-sucedido, de exercitar a capacidade de abstração dos participantes. Assim, foram produzidos diagramas de intervenções em espaços públicos, gerando cenários futuros que se assemelhavam, por vezes, a utopias ou distopias.

No último e quarto encontro, os adolescentes foram convidados a programar ações nos espaços públicos, estimulando o desenvolvimento do raciocínio reflexivo sobre a 
realidade concreta e a modelagem de cenários de mudança em contextos dinâmicos e imprevisíveis.

A práxis insurgente resultou na intervenção urbana na microescala, que ocorreu no dia 24 de junho de 2017, nas proximidades do Córrego Antonico. Foram ações coletivas de urbanismo tático na microescala sobre os espaços comuns da favela, resultantes das discussões e decisões dos participantes das oficinas.

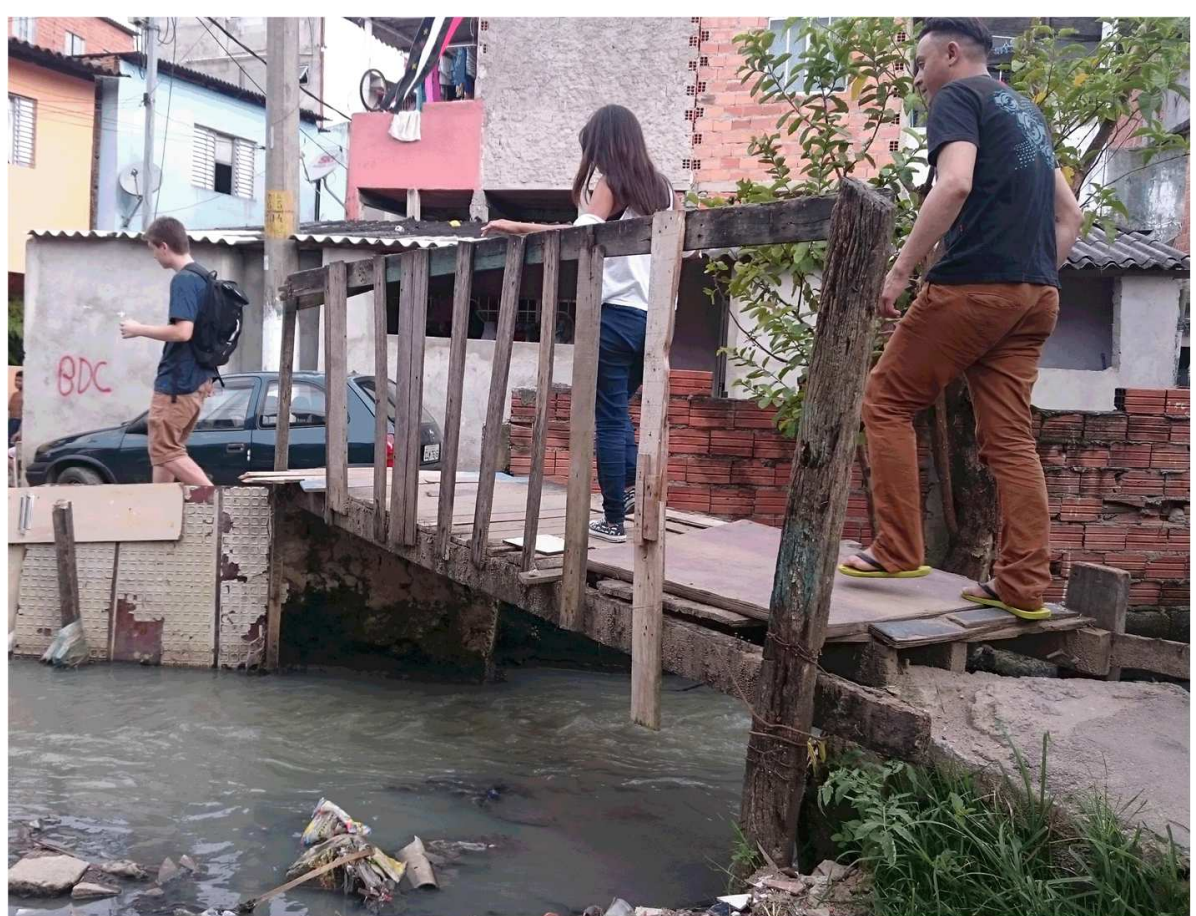

Figura 4: Práxis insurgente: Participantes do projeto atravessando a passarela sobre o Córrego Antonico. Fonte: acervo do autor, 2017.

Na práxis expressiva, foi realizada uma exposição itinerante para divulgar os resultados das oficinas para a comunidade de Paraisópolis. Foram produzidos 12 banners, expostos no Luau Paraisópolis, no dia 28 de abril, e no Centro Educativo Unificado (CEU Paraisópolis), de 22 a 29 de maio. O principal produto da práxis reflexiva foi a organização de uma mesa redonda, aberta ao público em geral, onde representantes da população local, profissionais e políticos debateram sobre o papel dos espaços públicos e a situação de negligência em que vivem os moradores das favelas.

\section{Aprender com o projeto: da experiência à ação}

É possível aprender com a prática de projeto colaborativo? O que se aprende? Como se aprende? Quem aprende? Pensar alternativas de projeto urbano pautadas no urbanismo tático, na colaboração entre os distintos agentes na transformação social da cidade através de intervenções urbanas na microescala, reorganizando microterritórios, foi uma estratégia de ação de um projeto que propôs situações 
dialógicas de práticas espaciais insurgentes por meio de cinco tipos de engajamento social.

No decorrer do trabalho de campo, quando se desenvolveu uma pesquisa-ação que se configurou como a oficina de projeto "Imagine Paraisópolis", foi possível refletir sobre o papel dos diversos agentes envolvidos (moradores, especialistas, governo e ONGs), bem como entender o papel das práxis plurais na produção dos comuns urbanos.

Ao atuar como mediadores das vozes conflitantes durante as oficinas, nos aproximamos dos distintos agentes, superando, assim, antagonismos políticos e promovendo os debates pautados pelas controvérsias (locais e globais), segundo a perspectiva da democracia agonística, citada anteriormente. As práxis plurais descritas e exemplificadas neste texto não devem ser entendidas, simplesmente, como um produto para aplicação em casos similares e, sim, confrontadas com a realidade concreta dos contextos urbanos, nas diversas situações de interação social entre os agentes envolvidos com o urbanismo tático.

Três temas merecem destaque nas discussões desta pesquisa: i) os ritmos assíncronos das atividades e as (operacionais) nos processos participativos; ii) o papel dos especialistas no engajamento (político) dos agentes locais envolvidos nas práxis plurais; e iii) as condições políticas, sociais e culturais para a autonomia local (política).

Primeiramente, o tempo possui uma relevância variável nos processos que envolvem diálogos democráticos, dependente dos contextos e das relações sociais, culturais, tecnológicas e políticas específicas entre os agentes e os objetos envolvidos no processo. As divergências nas expectativas dos especialistas, moradores e instituições de governo em relação à duração das ações ficou bastante evidente nas reuniões de planejamento realizadas em Paraisópolis. Desses conflitos, pode-se intuir lições importantes para minimizar as assincronias operativas intrínsecas às estruturas cotidianas locais e pensar alternativas de sincronia das atividades em projetos futuros, como a adoção de ciclos de projeto flexíveis e reversíveis orientados aos contextos.

Em relação ao engajamento (político) na transformação da cidade (na produção de lugares compartilhados), há o risco iminente de se permanecer em um dos extremos de um continuum do urbanismo social (prática espacial); seja priorizando as políticas públicas de produção do espaço urbano, definindo um pensamento prioritariamente estratégico (práxis estratégica), seja fomentando coletivos orientados para intervenções insurgentes nos espaços públicos, estruturando táticas urbanas (práxis experimental). Outras práxis plurais (colaborativa, reflexiva e expressiva) encontram-se entre esses polos, constituindo um espectro de ações mediadoras de conflito com temporalidades que podem se adaptar a cada caso.

Ainda se ressalta que o alcance pedagógico das práxis plurais se deu mais pelo intercâmbio de práticas e saberes do que pela transferência de conhecimentos ou a repetição de conjuntos de atividades previstas em manuais ou cartilhas de projeto. Os diferentes papéis que os especialistas cumprem em cada uma das cinco práxis sugere que há uma dimensão política disjuntiva que desafia o senso comum em relação à fixidez das relações hierárquicas entre produtores e consumidores. 
Como foi explicitado nesta pesquisa, as condições políticas, sociais e culturais por uma autonomia criativa local (política) não atuam sobre uma prática espacial isoladamente. Ao contrário, propõe-se que as transformações urbanas resultam da atuação conjunta (sistêmica) (indissociável) das práxis plurais, resultando em uma sequência de práticas que situam os agentes envolvidos em diferentes relações de poder, dependendo do contexto local.

\section{CONCLUSÃo}

Imaginar a cidade e compartilhar lugares para produção de comuns urbanos exige uma transformação social que nos sugere a ideia de utopia. Trata-se, contudo, de um devir que, ao se constituir no desenrolar de uma experiência no espaço-tempo, se desdobra na forma de disjunções socioespaciais, as quais promovem a ideia de autonomia e auto-organização para a produção, uso e apropriação de espaços públicos.

A abertura democrática possibilitou aos movimentos sociais novos horizontes de ação, mas ainda com riscos e limitações indefinidos. Seja como urbanismo participativo, ativismo urbano, urbanismo emergente, urbanismo tático ou outras denominações, tais noções carecem de aprofundamento teórico, desenvolvimento metodológico e elaboração empírica.

A tendência homogeneizante atribuída à maioria das práticas democráticas participativas resulta na confusão conceitual tanto das iniciativas hegemônicas quanto dos projetos de cidadania insurgente. A seu turno, a ausência de rigor científico, as finalidades genéricas, a participação fantasma, a precariedade comunicacional, e as temporalidades assíncronas são alguns dos riscos aos empreendimentos sociais voltados para práxis plurais de urbanismo participativo.

O futuro do urbanismo tático depende, em grande parte, do engajamento dos especialistas, agentes locais, movimentos sociais, ONGs e outras instâncias comunitárias, na resistência às estruturas institucionalizadas de governança e às práticas pretensamente "racionalistas" de planejamento urbano. Os processos participativos devem ir além das premissas urbanas ortodoxas e promover a autonomia dos movimentos sociais que propõem o desenvolvimento sócio-espacial dos assentamentos precários.

Retoma-se, assim, a ecologia de saberes, mencionada no início do artigo, como a realização de utopia no presente, uma heterotopia, uma forma progressista de crítica interna à concepção utópica, que pode apontar para sua promessa de emancipação, reafirmando o pensamento pós-abissal na (re) configuração das epistemologias do sul, contra o colonialismo e as práticas capitalistas heterônomas que se vinculam ao pensamento abissal.

Por fim, este artigo apresentou as práxis plurais como perspectiva de resistência política modalizada por uma ecologia de saberes para a articulação dos comuns urbanos, especialmente associados aos conceitos de lugar e cotidiano, por meio de práticas espaciais orientadas para o desenvolvimento sócio-espacial. 


\section{Agradecimentos}

Agradecemos a Ana Pernambuco, Angélica Alvim, Fernando Botton, Kamilla Santos, Luiz Guilherme Castro e Maria Tereza Fedeli pela participação no projeto; à Universidade Presbiteriana Mackenzie, ao Projeto Einstein Paraisópolis e à Associação de Moradores de Paraisópolis pelo apoio institucional; à Fundação Alphaville pelo apoio financeiro. Agradecemos aos revisores, pelo encorajamento, sugestões e críticas que contribuíram para a elaboração de uma perspectiva crítica sobre o tema. $O$ presente trabalho foi realizado com apoio da Coordenação de Aperfeiçoamento de Pessoal de Nível Superior - Brasil (CAPES) - Código de Financiamento 001.

\section{REFERÊNCIAS}

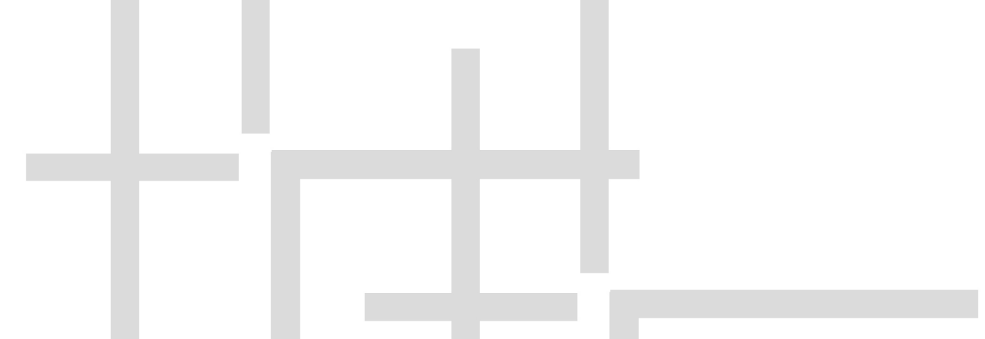

AGNEW, J. Place and politics. Boston: Allen \& Unwin, 1987.

AGNEW, J. Representing Space: Space, Scale and Culture in Social Science. In:

DUNCAN, J. (org.). Place, Culture, Representation. Nova lorque: Routledge, 1993. p. 251-271.

ALEXANDER, C., ISHIKAWA, S., SILVERSTEIN, M., JACOBSON, M., FIKSDAHL-KING, I., \& ANGEL, S. Uma linguagem de padrões: a pattern language. Porto Alegre: Bookman, 2013.

ARNSTEIN, S. A ladder of Citizen Participation. Journal of the American Institute of Planners, [s. l.], v. 8, n. 3, p. 216-224, 1969. Disponível em: https://www.tandf online.com/toc/rjpa19/35/4. Acesso em: 10 jan. 2021.

BORCH, C.; KORNBERGER, M. Urban Commons: Rethinking the City. Londres: Routledge, 2015.

BRENNER, N. Espaços da Urbanização: o urbano a partir da teoria crítica. Rio de Janeiro: Letra Capital, Observatório das Metrópolis, 2018.

CARLOS, A. F. A O espaço-tempo da práxis urbana na modernidade. Boletim Paulista de Geografia, São Paulo, v. 100, p. 1-16, 2018. Disponível em: https://gesp.fflch.usp. br/sites/gesp.fflch.usp.br/files/Espa\%C3\%A7o-Tempo\%20da\%20Vida\%20Cotidi ana\%20na\%20Metr\%C3\%B3pole_.pdf. Acesso em: 10 jan. 2021.

CARLOS, E. Movimentos sociais e instituições participativas: Efeitos do engajamento institucional nos padrões de ação coletiva. Revista Brasileira de Ciências Sociais, São Paulo, v. 30, n. 88, p. 83-98, jun. 2015. Disponível em: https://www.scielo. $\mathrm{br} / \mathrm{j} / \mathrm{rbcsoc} / \mathrm{a} / \mathrm{k} 8 \mathrm{sNWd8Drjt7f9LHwSXSWMP/abstract/?lang=pt.} \mathrm{Acesso} \mathrm{em:}$ 10 jan. 2021 
CRUZ, S. R. S.; PAULINO, S. R. Urban Commons in Active Mobility Experiences. International Journal of the Commons, Reino Unido, v. 14, n. 1, p. 539-552, 2020. Disponível em: https://www.thecommonsjournal.org/37/volume/14/issue/1/. Acesso em: 10 jan. 2021.

DARDOT, P.; LAVAL, C. Comum: Ensaio sobre a Revolução no Século XXI. São Paulo: Boitempo, 2016.

Del GAUDIO, C. Os desafios para o design no âmbito social e as perspectivas futuras: o conceito de infraestruturação e a redefinição do papel do designer. In: Del GAUDIO, C.; PEREIRA, A. F. (orgs.). Ecovisões projetuais: pesquisas em design e sustentabilidade no Brasil. São Paulo: Blucher, 2017, p. 65 -80.

Del GAUDIO, C., Franzato, C., \& Oliveira, A. Sharing design agency with local partners in participatory design. International Journal of Design, Taiwan, v. 10, n. 1, p. 53-64, 2016. Disponível em: 718 (ijdesign.org). Acesso em: 10 jan. 2021.

FEINBERG, A.; GHORBANI, A.; HERDER, P. Diversity and Challenges of the Urban Commons: A Comprehensive Review. International Journal of the Commons, Reino Unido, v. 15, n. 1, p. 1-20, 01 abr. 2021. Disponível em: https://www. thecommonsjournal.org/38/volume/15/issue/1/. Acesso em: 10 jan. 2021.

FONTES, A. S. Intervenções Temporárias, Marcas Permanentes: Apropriações, Arte e Festa na Cidade Contemporânea. Rio de Janeiro: Casa da Palavra/FAPERJ, 2013.

FOSTER, S.; LAIONE, C. The city as a commons. Yale Law \& Policy Review, New Haven EUA, v. 281, n. 34, p. 281-349, 2016. Disponível em: https://ylpr.yale.edu/citycommons. Acesso em: 10 jan. 2021.

FOSTER, S.; LAIONE, C. Ostrom in the City: Design Principles and Practices for the Urban Commons. In: COLE, D.; HUDSON, B.; ROSENBLOOM, J. (eds.). Routledge Handbook of the Study of the Commons. 1. ed. Londres: Routledge, 2019. p. 1-24.

GEHL, J. Cidades para pessoas. São Paulo: Perspectiva, 2013.

HALL, S. Da diáspora. Identidades e mediações culturais. Belo Horizonte: Editora UFMG, 2013.

HARDIN, G. The Tragedy of the Commons. Science, Nova lorque, v. 162, 13 dez. 1968, p. 1243-1248. Disponível em: https://www.science.org/doi/abs/10.1126/science. 162.3859.1243. Acesso em: 10 jan. 2021.

HARDT, M.; NEGRI, A. Bem-estar Comum. Rio de Janeiro: Record, 2009.

HARVEY, D. Cidades Rebeldes: do direito à cidade à Revolução Urbana. São Paulo: Martins Fontes, 2014.

HARVEY, D. Contested Cities: Social Process and Spatial Form. In: JEWSON, N.; MACGREGOR. S. (org.). Transforming Cities. Londres: Routledge, 1997. p. 19-27. 
HESS, C. Mapping the New Commons. In: 12TH BIENNIAL CONFERENCE OF THE INTERNATIONAL ASSOCIATION FOR THE STUDY OF THE COMMONS, Anais [...]. Cheltenham: University of Gloucestershire, 2008.

HILLGREN, P.A.; SERAVALLI, A.; EMILSON, A. Prototyping and infrastructuring in design for social innovation. CoDesign, v. 7, n. 3-4, p. 169-183, 2011. Disponível em: http://dx.doi.org/10.1080/15710882.2011.630474. Acesso em: 10 jan. 2021.

HOLSTON, J. Cidadania insurgente: disjunções da democracia e da modernidade no Brasil. São Paulo: Companhia das Letras, 2013.

HUYBRECHTS, L. et al. Democratic dialogues that make cities 'work'. Strategic Design Research Journal, São Leopoldo - RS, v. 9, n. 2, p. 100-111, maio/ago., 2016. Disponível em: http://revistas.unisinos.br/index.php/sdrj/article/view/sdrj.2016. 92.05. Acesso em: 10 jan. 2021.

JACOBS, J. The death and life of Great American cities. Harmondsworth: Penguin Books, 1961.

LACAZE, J-P. Os métodos do urbanismo. Campinas, São Paulo: Papirus, 1993.

LINEBAUGH, P. The Magna Carta manifesto: Liberties and commons for all. Berkeley, Califórnia: University of California Press, 2008.

MANZINI, E. Design when everybody designs. An introduction to design for social innovation. Cambridge: MIT Press, 2015.

MONTANER, J. M. Do diagrama às experiências, rumo a uma arquitetura de ação. São Paulo: Editorial Gustavo Gili, 2017.

MOORE, S. A. Tecnologias, lugar e regionalismo não moderno. In: SYKES, K. (org.) 0 campo ampliado da arquitetura. São Paulo: Cosac Naify, 2013. p. 278-293.

MOUFFE, C. Sobre o político. São Paulo: Editora WMF Martins Fontes, 2015.

OSTROM, E. Governing the commons: The evolution of institutions for collective action. Cambridge, Reino Unido: Cambridge University Press, 1990.

PARKER, P. Ed.; SCHMIDT, S. Enabling urban commons. CoDesign, Reino Unido, v. 13, n. 3, p. 202-2013, 01 ago. 2017. Disponível em: https://www.tandfonline.com/doi/ abs/10.1080/15710882.2017.1355000. Acesso em: 20 fev. 2021.

ROSA, M. Planejamento: práticas urbanas criativas. São Paulo: Editora de Cultura, 2011.

SURI, J. F. The experience of evolution: developments in design practice. The Design Journal, Londres v. 6, n. 2, p. 39-48, 2003. Disponível em: https://www.tandf online.com/doi/abs/10.2752/146069203789355471. Acesso em: 18 fev. 2021.

SOUZA, M. L. Os conceitos fundamentais da pesquisa sócio-espacial. Rio de Janeiro: Bertrand Brasil, 2013.

STAVRIDES, S. Common Space: The city as commons. Londres: Zed Books, 2016. 
TELI, M.; BORDIN, S.; BLANCO, M. M.; ORABONA, G.; De ANGELI, A. Public design of digital commons in urban places: A case study. International Journal of Human Computer Studies, Reino Unido, v. 81, p. 17-30, set. 2015. Disponível em: https://www.sciencedirect.com/science/article/abs/pii/S1071581915000269. Acesso em: 18 de fev. 2021.

THIOLLENT, M. Metodologia da Pesquisa-Ação. São Paulo: Cortez, 2011.

WISNIK, G. Projeto e Utopia: de volta à arena pública. In: NOVAES, A. (org.). Mutações: o Novo Espírito Utópico. São Paulo: Edições Sesc São Paulo, 2016. p. 341-349. 